\title{
Neuropsychological assessment in HTLV-1 infection: a comparative study among TSP/HAM, asymptomatic carriers, and healthy controls
}

\author{
M T T Silva, P Mattos, A Alfano, A Q-C Araújo
}

See end of article for authors' affiliations

.....................

Correspondence to: $\operatorname{Dr} A$ Q-C Araújo, Rua Cel Moreira César 107/1001 CEP 24230-050 Icaraí, Niterói, Rio de Janeiro, Brazil; abelardo@ufri.br

Received

10 November 2002

Accepted in revised form

10 February 2003
Background: Human T cell lymphotropic virus type 1 (HTLV-I) can cause tropical spastic paraparesis/ HTLV-1 associated myelopathy (TSP/HAM) and adult T cell leukaemia/lymphoma. More recently other diseases such as isolated peripheral polyneuropathy, myopathy, artropathy, and uveitis have been associated with this retrovirus. Only a few uncontrolled studies, without necessary exclusion criteria, have described mild cognitive deficits among TSP/HAM patients. To further clarify this the authors evaluated, through neuropsychological testing patients with TSP/HAM and asymptomatic infected carriers, comparing both groups with healthy controls.

Objectives: To verify the presence of cognitive deficits among TSP/HAM patients and asymptomatic HTLV-1 infected carriers. In addition, the authors aimed to investigate if these deficits correlated with the degree of motor impairment in TSP/HAM patients.

Methods: From a cohort of 501 HTLV-1 infected people the authors selected, according to predefined inclusion and exclusion criteria, 40 asymptomatic HTLV-1 carriers and 37 TSP/HAM patients. Neuropsychological testing was blindly performed in both groups and their scores were compared with those obtained from controls.

Results: Both the HTLV-1 carrier group and the group of patients with TSP/HAM exhibited a lower performance in neuropsychological tests when compared with controls. Asymptomatic infected carriers and TSP/HAM patients did not differ in their cognitive results. Also, there was no relation between the degree of motor disability and cognitive deficits in the TSP/HAM group. Psychomotor slowing and deficits in the some domains characterised the neuropsychological impairment in HTLV-1 infection: verbal and visual memory, attention and visuomotor abilities.

Conclusions: TSP/HAM as well as asymptomatic infection can be associated with mild cognitive deficits. This finding, if confirmed by further studies, will permit the inclusion of cognitive impairment among the neurological manifestations of HTLV-1.
$\mathrm{T}$ he human T cell lymphotropic virus type 1 (HTLV-1) is the aetiological agent of tropical spastic paraparesis/HTLV-1 associated myelopathy (TSP/HAM) ${ }^{1}$ and adult $\mathrm{T}$ cell leukaemia/lymphoma (ATLL). ${ }^{2}$ It is also implicated in other clinical conditions, such as peripheral neuropathy, myopathy, and uveitis. ${ }^{3-6}$ The interest for cognitive disturbances in HTLV- 1 infection started after an increasing number of reports describing brain abnormalities in magnetic resonance imaging (MRI) of TSP/HAM patients. Because the white matter lesions of TSP/HAM are in some aspects similar to those observed in patients with multiple sclerosis or in HIV infected people (both conditions with well known cognitive impairment), the cognitive deficits in TSP/HAM patients are also supposed to occur. Yet, only a few papers about this subject are available in the literature. Most of the published literature on cognitive disturbances in TSP/HAM describes psychomotor slowing, attention deficits as well as visual and working memory deficits. However, a number of methodological problems arise from these series. Extensive batteries for assessing cognitive dysfunction have been used in only three of the nine available papers, ${ }^{7-9}$ and in only one a control group was used. ${ }^{9}$ The remaining papers are either case reports, ${ }^{10-12}$ studies on cognitive event related potentials, ${ }^{13}$ or epidemiological surveys on the seroprevalence of HTLV- 1 in demented patients. ${ }^{14} 15$

Therefore, there have been no entirely satisfactory studies looking for cognitive deficits in HTLV-1 infected people using a representative sample, comparing it with a control group and using a full battery of neuropsychological tests. The aims of this study are ( 1 ) to investigate the existence of cognitive dis- turbances associated with TSP/HAM and whether it bears any correlation with the degree of neurological disability of such people, and (2) to check whether minor cognitive deficits are present in asymptomatic carriers (AC) of the virus.

\section{METHODS}

TSP/HAM patients and AC were selected from a cohort of 501 HTLV-1 infected people from the Evandro Chagas Research Institute/FIOCRUZ, Rio de Janeiro, Brazil. Forty AC and 37 TSP/HAM patients were selected in accordance with inclusion and exclusion criteria. The control group included 111 healthy people from a Brazilian normative databank of more than 300 persons. This databank has been previously created as a control group for neuropsychological testing. Controls have been matched with cases by age, sex, and educational level. The inclusion criteria for the HTLV-1 group were: HTLV-1 antibodies in serum (in AC group) and serum and CSF (in TSP/HAM group) by ELISA and western blot analysis; TSP/HAM diagnosis according to Osame's criteria ${ }^{16}$; age over 18 and formal consent. The exclusion criteria for all the studied groups were: history, clinical or laboratory evidences of overt dementia, mood or psychiatric disturbances, traumatic brain injury, stroke, B12/folate deficiency, hypothyroidism,

Abbreviations: HTLV-1, human T cell lymphotropic virus type 1 ; TSP/HAM, tropical spastic paraparesis/HTLV-1 associated myelopathy; $A C$, asymptomatic carriers 
Table 1 Demographic features of the groups

\begin{tabular}{lllll}
\hline & TSP/HAM $(\mathrm{n}=37)$ & $\mathrm{AC}(\mathrm{n}=40)$ & HTLV-I negative $(\mathrm{n}=111)$ & $\mathrm{p}$ Value \\
\hline Age $^{*}$ & $50.5(9.1)$ & $47.1(8.9)$ & $46.6(11.8)$ & $0.07 \ddagger$ \\
Schooldays* $_{\text {Female }}$ & $8.4(4.9)$ & $9.6(4.6)$ & $9.8(4.8)$ & $0.07 \ddagger$ \\
\hline
\end{tabular}

TSP/HAM, tropical spastic paraparesis/HTLV-I associated myelopathy; AC, asymptomatic carriers. *Average (SD); †absolute value; $\ddagger$ Kruskall-Wallis; $\S \chi^{2}$ test.

alcoholism, drug addiction, HIV infection, syphilis and epilepsy; severe or non-corrected deafness or visual deficits; motor impairment in arms or hands; use of psychotropic drugs in the past four weeks; formal education level under five years and lack of fluency in the Portuguese language. All the HTLV-1 infected subjects were submitted to a clinical interview and a full neurological examination by one of the authors (MTTS). In addition, TSP/HAM patients were further classified into mildly, moderately, or severely disabled according to a previously validated disability scale (Evandro Chagas Clinical Institute Disability Scale for TSP/HAM). This scale bears a good correlation with the Kurtzke's disability status scale used in patients with multiple sclerosis and also widely used in TSP/HAM. ${ }^{17}$ After fulfilling the inclusion criteria, TSP/ HAM patients and AC were sent to a formal neuropsychological testing performed by a trained psychologist (AA). An expert in neuropsychology (PM), who was blind to the clinical status of each individual corrected and analysed the tests. The neuropsychological battery used was: Mini-mental State Examination (MMSE), Digit Symbol (DSY), Grooved Pegboard with dominant and non-dominant hands (GDOM and GNDOM, respectively), Stroop Test, consisting in Color (STRC) and Color-Word (STRCW), verbal semantic and phonetic fluency (animals, fruits, letters F, A and S), Digit Span Forwards and Backwards (DSF and DSB, respectively), Rey-Osterrieth Complex Figure (REY), Logical Memory I/II (LM), Auditory-Verbal Learning Test (RAl-5, RAF-RAF3,
REVI-2 and REC), and parts A and B of Trail Making Test (TRAILA/B). These tests where chosen because they are extremely sensitive to minimal brain dysfunction and because they have been previously validated in HIV infected people. ${ }^{18}$ Those tests investigate the main neuropsychological deficits related to subcortical involvement: attentional dysfunction (including mental flexibility or alternate attention), memory disturbances (visual and verbal), visuoperceptual deficits and visuomotor dexterity or speed..$^{19}$ This profile is clearly distinct from the one seen in cortical involvement. ${ }^{20}$ An in depth description of these tests can be found elsewhere. ${ }^{21}$ All the crude scores were analysed by a statistical software (Epinfo version 6.0, DPHSI, CDC, USA). Non-parametric tests $\left(\chi^{2}\right.$, Kruskal-Wallis, and Mann-Whitney) were used and a $\mathrm{p}$ value $<0.05$ was considered significant.

\section{RESULTS}

Table 1 shows the demographic features of the three groups. There were no significant differences in terms of age, sex, and educational level. We observed significant statistical differences in the raw scores of all tests when comparing the HTLV-1 positive group with the HTLV-1 negatives (table 2). There were also significant differences in almost all tests when comparing the scores of the AC group with the HTLV-1 negative group (table 2). In contrast, the AC group did not differ significantly from the TSP/HAM group, except in the part A of the Trail Making Test, Digit Symbol, Digit Span Backward, and in some

Table 2 Crude scores in the neuropsychological battery* (abbreviation list in appendix)

\begin{tabular}{|c|c|c|c|c|c|c|c|c|c|}
\hline & $\begin{array}{l}\text { HTLV negative } \\
(\mathrm{n}=111)\end{array}$ & $\begin{array}{l}\text { HTLV positive } \\
(\mathrm{n}=77)\end{array}$ & p Value & $\begin{array}{l}\text { Asymptomatic } \\
(n=40)\end{array}$ & $\begin{array}{l}\text { HTLV negative } \\
(n=111)\end{array}$ & p Value & $\begin{array}{l}\text { Asymptomatic } \\
(n=40)\end{array}$ & $\begin{array}{l}\text { HAM/TSP } \\
(n=37)\end{array}$ & p Value \\
\hline DSY & 51 (14-88) & $29(2-92)$ & $<0.001$ & 32.5 (7-59) & 51 (14-88) & $<0.001$ & 32.5 (7-59) & 26.5 (2-92) & 0.0350 \\
\hline GDOM & $66(54-123)$ & 85 (59-187) & $<0.001$ & $81.5(59-156)$ & $66(54-123)$ & $<0.001$ & $81.5(59-156)$ & 88 (61-187) & 0.1378 \\
\hline GNDOM & $76(61-141)$ & $86(38-250)$ & $<0.001$ & 88.5 (64-196) & $76(61-141)$ & 0.6084 & $88.5(64-196)$ & $83(38-250)$ & 0.5678 \\
\hline STRC & $112(101-112)$ & $112(44-112)$ & $<0.001$ & $112(11-112)$ & $112(101-112)$ & 0.138 & $112(44-112)$ & $112(69-112)$ & 0.4313 \\
\hline STRCW & $86(42-112)$ & $70(3-112)$ & $<0.001$ & $67(11-108)$ & $86(42-112)$ & 0.024 & $67(11-108)$ & $70(3-112)$ & 0.4879 \\
\hline $\mathrm{F}$ & $13.5(3-26)$ & $9(8-20)$ & $<0.001$ & $9.5(5-16)$ & $13.5(3-26)$ & $<0.001$ & $9.5(5-16)$ & $9(4-20)$ & 0.6855 \\
\hline A & $13(3-24)$ & $9(2-18)$ & $<0.001$ & $8(6-17)$ & $13(3-24)$ & $<0.001$ & $8(6-17)$ & $9(2-18)$ & 0.1567 \\
\hline S & $13(3-25)$ & $9(2-17)$ & $<0.001$ & $9.5(5-14)$ & $13(3-25)$ & $<0.001$ & $9.5(5-14)$ & $8(2-17)$ & 0.5306 \\
\hline Animals & $19(9-32)$ & $14(3-28)$ & $<0.001$ & $13(7-28)$ & $19(9-32)$ & $<0.001$ & $13(7-28)$ & $14(3-23)$ & 0.2759 \\
\hline Fruit & $16(6-29)$ & $12(4-23)$ & $<0.001$ & $13(10-23)$ & $16(6-29)$ & $<0.001$ & $13(10-23)$ & $14(4-20)$ & 0.2476 \\
\hline DSF & $6(3-8)$ & $2(2-8)$ & 0.3197 & $6(4-8)$ & $6(3-8)$ & 0.7742 & $6(4-8)$ & $6(2-7)$ & 0.3082 \\
\hline DSB & $4(2-7)$ & $4(1-7)$ & 0.4045 & $4(2-7)$ & $4(2-7)$ & 0.6127 & $4(2-7)$ & $4(1-7)$ & 0.0313 \\
\hline REY 1 & $32(18-32)$ & $32(5-32)$ & 0.1569 & $32(13-32)$ & $32(18-32)$ & 0.6084 & $32(13-32)$ & $32(5-32)$ & 0.2865 \\
\hline REY2 & $20(4-31)$ & $15(0-30)$ & $<0.001$ & $15(0-30)$ & $20(4-31)$ & $<0.001$ & $15(0-30)$ & $16(0-28)$ & 0.7322 \\
\hline REY\% & $35(3-84)$ & $52(6-100)$ & $<0.001$ & $53(6-100)$ & $35(3-84)$ & 0.0013 & $53(6-100)$ & $47(13-100)$ & 0.7440 \\
\hline LMI & $24(13-36)$ & $19(3-43)$ & $<0.001$ & $20(9-43)$ & $24(13-26)$ & $<0.001$ & $20(9-43)$ & $18(3-34)$ & 0.1807 \\
\hline LM2 & $19(6-30)$ & $15(0-43)$ & $<0.001$ & $15.5(5-43)$ & $19(6-30)$ & 0.0085 & $15.5(5-43)$ & $14(0-35)$ & 0.3070 \\
\hline LM\% & $20(4-63)$ & $22(15-100)$ & 0.8585 & 21.5 (8-62) & $20(4-63)$ & 0.6700 & $21.5(8-62)$ & $24(-15$ to 100$)$ & 0.6794 \\
\hline RAl & $6(1-12)$ & $5(2-11)$ & 0.0034 & $5(3-11)$ & $6(1-12)$ & 0.1228 & $5(3-11)$ & $5(2-9)$ & 0.1396 \\
\hline RA5 & $12(7-15)$ & $11(1-15)$ & 0.0022 & $11(5-14)$ & $12(7-15)$ & 0.0432 & $11(5-14)$ & $10(1-15)$ & 0.2620 \\
\hline RAF & $6(0-11)$ & $5(3-11)$ & 0.1260 & $5(2-10)$ & $6(0-11)$ & 0.2011 & $5(2-10)$ & $5(-3$ tol 1$)$ & 0.8974 \\
\hline RAF2 & $-2(-11$ to 4$)$ & $-3(-8$ to 2$)$ & 0.4992 & $-3(-8$ to 0$)$ & $-2(-11$ to 4$)$ & 0.4753 & $-3(-8$ to 0$)$ & $-2(-6$ to 2$)$ & 0.8441 \\
\hline RAF3 & $0(-4$ to 6$)$ & $0(-3$ to 3$)$ & 0.1690 & $1(-3$ to 3$)$ & $0(-4$ to 6$)$ & 0.0199 & $1(-3$ to 3$)$ & $0(-3$ to 3$)$ & 0.0374 \\
\hline REV 1 & $10(2-15)$ & $8(1-14)$ & 0.0012 & $9(3-13)$ & $10(2-15)$ & 0.0257 & $9(3-13)$ & $8(1-14)$ & 0.3577 \\
\hline REV2 & $10(4-15)$ & $8(1-14)$ & 0.0150 & $8.5(5-14)$ & $10(4-15)$ & 0.2616 & $8.5(5-14)$ & $7(1-12)$ & 0.0466 \\
\hline REC & $28(20-30)$ & $28(10-30)$ & 0.0811 & $28(23-30)$ & $28(20-30)$ & 0.4266 & $28(23-30)$ & $27(10-30)$ & 0.2611 \\
\hline TRAIL A & $54(24-120)$ & $59(22-300)$ & 0.0024 & $56(22-120)$ & $54(24-120)$ & 0.1466 & $56(22-120)$ & $71(31-300)$ & 0.0255 \\
\hline TRAIL B & 76 (34-300) & $139(56-300)$ & $<0.001$ & $155(56-300)$ & $79(34-300)$ & $<0.001$ & $155(56-300)$ & $134(58-300)$ & 0.5816 \\
\hline TRAIL \% & $44(0-436)$ & $138(0-466)$ & $<0.001$ & $172.5(29-466)$ & $44(0-436)$ & $<0.001$ & $172.5(29-466)$ & $104(0$ to 385$)$ & 0.0049 \\
\hline
\end{tabular}

*All the scores are represented in median (minimum-maximum) and the non-parametric test used was Mann-Whitney test. 
Table 3 Summary of published studies on cognitive dysfunction in HTLV-I infection

\begin{tabular}{|c|c|c|c|c|}
\hline Author & Year & Study & $\begin{array}{l}\text { Number of } \\
\text { cases }\end{array}$ & Control group \\
\hline Sulkava et al ${ }^{15}$ & 1987 & $\begin{array}{l}\text { HIV and HTLV-I seroprevalence among } \\
\text { demented patients in Finland }\end{array}$ & 69 & No \\
\hline Cartier et $a^{\prime \prime}{ }^{1}$ & 1990 & Case report & 1 & Not applicable \\
\hline Cartier et aP & 1992 & $\begin{array}{l}\text { Neuropsychological assessment in } \\
\text { TSP/HAM patient }\end{array}$ & 12 & No \\
\hline Lycke et $a l^{\prime 2}$ & 1993 & Case report & 1 & Not applicable \\
\hline Fukushima et $a^{13}$ & 1994 & $\begin{array}{l}\text { Cognitive assessment by evocated } \\
\text { potentials }\end{array}$ & 14 & 36 HTLV-I negative \\
\hline Castillo et al & 1995 & $\begin{array}{l}\text { Cognitive assessment by evocated } \\
\text { potentials, WAIS* and Benton's test }\end{array}$ & 16 & 10 patients with seronegative myelopathy \\
\hline Kira et $a^{l^{4}}$ & 1997 & $\begin{array}{l}\text { HTLV-I seroprevalence in demented } \\
\text { patients }\end{array}$ & 130 & 139 \\
\hline Cartier et $a^{10}{ }^{10}$ & 1997 & Case report & 1 & Not applicable \\
\hline Cartier et a ${ }^{\beta}$ & 1999 & $\begin{array}{l}\text { Cognitive assessment with WAIS* and } \\
\text { Benton's test }\end{array}$ & 43 & No \\
\hline
\end{tabular}

components of the Auditory-Verbal Learning Test (table 2). In addition, except for the Grooved Pegboard with no-dominant hand test, the performance in the neuropsychological tests seemed not to be affected by the severity of the neurological disability.

\section{DISCUSSION}

In our sample, HTLV-1 infection was associated with mild cognitive deficits, characterised by impairments in psychomotor speed, verbal fluency, verbal and visual memory, selective and alternate attention (flexibility), and visuoconstructive abilities. The AC group revealed a worse performance in several tests when compared with the control group (table 2). The association between "asymptomatic" infection and mild cognitive deficit was also supported by a similar performance when we compared the AC group with the TSP/HAM group (table 2). A confounding factor (such as mood disorder) in the TSP/HAM group that could bias the results is weakened by this finding. Furthermore, the severity of the motor impairment was not associated with a worse performance in the TSP/HAM group. This suggests that either HTLV-1 infection in itself could be responsible for this mild cognitive decline or that, in fact, some of these so called asymptomatic carriers are true neurological patients with a subclinical form of HTLV-1 associated cognitive dysfunction without myelopathy.

The first reports on the presence of MRI brain lesions in TSP/HAM appeared soon after the initial TSP/HAM description. ${ }^{22}{ }^{23}$ The prevalence of this finding is said to be around $50 \%$ to $80 \%$, making us believe that these lesions were not restricted to the spinal cord. These white matter lesions are supposed to be caused by a chronic perivascular inflammation. Akizuki et al demonstrated perivascular lymphocytic infiltration in the CNS, suggesting that vasculitis is an important pathological feature of TSP/HAM. ${ }^{24}$ This may explain the diffuse nature of such lesions, suggesting that TSP/HAM is in fact a chronic multifocal leucoencephalopathy.

The pathogenesis of TSP/HAM is not fully understood. The findings of infected $\mathrm{T}$ lymphocytes in the CNS suggest transendothelial migration and passage of these cells through the blood-brain barrier. This is regulated by cellular adhesion molecules and some chemokines. ${ }^{25}{ }^{26}$ The interaction between infected lymphocytes and CD8+ cells in the CNS results in release of cytokines, as TNF $\alpha$, IL1, IL2, and IL6, with subsequent destruction of glial tissue. ${ }^{27}$ It has been shown that the supernatant of HTLV-l infected cell cultures inhibits endothelial growth and increases fibroblast growth, being this phenomenon related to TNF $\alpha$ production. ${ }^{28}$ These observations explain the pathogenic nature of two pathological features: the fibrous thickness of leptomeninges and adventitia (by fibroblast proliferation) and lipohyalinosis of small vessels (by suppression of endothelial cell growth). Moreover, TNF $\alpha$ has a toxic effect on endothelial cells and an inhibitory effect on DNA synthesis that changes the endothelial morphology and compromises the blood circulation. ${ }^{29}$ Another study that reinforces the vascular inflammation mechanism in cerebral lesions is Kira's study. ${ }^{14}$ After analysis of the HTLV-1 seroprevalence in a cohort of demented patients, they found an association between vascular dementia and HTLV-1 seropositivity. They also demonstrated a relation between HTLV-1 and peripheral atherosclerosis, heart disease, and systemic arterial hypertension. All these data strongly suggest that white matter brain lesions may be inflammatory in nature and that a vasculitis is implicated in its pathogenesis.

If we use multiple sclerosis and HIV infection as paradigms for conditions in which cognitive dysfunction is associated with white matter abnormalities, it is reasonable to suggest that the same happens in HTLV-1 associated cognitive deficits, although they are seem to be milder. White matter is critical to motor, sensory, and visual systems. Lesions in such subcortical structure contribute to a variety of neurobehavioural syndromes. Because of the great connection between frontal lobes and more posterior regions of the brain, and the ratio of white to gray matter is higher in the right than the left hemisphere (especially in the frontal lobes), diffuse white matter lesions would preferentially disrupt attentional systems, frontal lobe function, mental flexibility, visuospatial skills, and emotional status. ${ }^{30}$ In fact, if at least one physiological function of the frontal lobe is to integrate networks for combined action, white matter multifocal partial lesions (like in multiple sclerosis, HIV encephalopathy, and even TSP/HAM) could collectively disrupt internetwork coordination and therefore lead to the manifestations of a "frontal network syndrome" ${ }^{31}$ This is characterised by psychomotor slowing, decreased verbal fluency, memory deficits, impaired vigilance, selective and alternate attention deficits (flexibility), and impairment in visuoconstructive abilities. Additionally, there is evidence that brain white matter volume declines with age. ${ }^{32}$ This observation implies that mental changes associated with normal aging may be in part attributable to myelin loss, and such changes are very similar to "frontal network syndrome". In short, white matter is a crucial component of neural networks, contributing to many syndromes seen in behavioural neurology; the effects of white matter diseases should therefore be clinically important.

A review of the literature about cognitive deficits in HTLV-1 infection detected only nine reports (table 3), most of them uncontrolled and small. Of these, only one is, to some extent, similar to ours. ${ }^{8}$ However, the main differences between both studies are that neither necessary exclusion criteria (as neuropsychological deficits may be correlated to a myriad of conditions) nor a control group were used in that study. 
Another interesting point is the reason by which a few HTLV-1 infected people develop TSP/HAM. It has been shown that TSP/HAM patients have a higher proviral load than AC. ${ }^{33}{ }^{34}$ This leads to a pronounced inflammatory response that is considered the basic mechanism of myelopathy. However, subjects with other neurological diseases, as peripheral neuropathy, myopathy or isolated neurological signs in clinical examination $^{35}{ }^{36}$ have a proviral load as high as TSP/HAM (Andrada-Serpa MJ, personal communication). Therefore if HTLV-l infected people with cognitive dysfunction have a mean proviral load similar to the one found in TSP/HAM patients they could either represent a new subset of neurological manifestation of HTLV-1 (HTLV-1 associated cognitive dysfunction) or an initial, or subclinical, form of TSP/HAM.

Unfortunately there are no data regarding necropsy findings in AC people to determine whether they do have white matter lesions in their brain similar those found in TSP/ HAM. In addition, the real prevalence of these lesions in brain MRI in AC people is not completely known. However, Kira et al have demonstrated that the prevalence of white matter lesions in brain MRI is higher in asymptomatics than in HTLV-I negative controls. ${ }^{37}$ On the other hand, it is well known that HIV infected people can present cognitive deficits very early, sometimes before the appearance of MRI abnormalities. ${ }^{38} 39$ If the same applies to HTLV-1 this could justify the presence of cognitive deficit in AC even with normal brain MRI. The demonstration of mild cognitive deficits in AC is of utmost importance; if these results can be replicated in a larger sample, it will be possible to affirm that mild cognitive could be part of the neurological spectrum of HTLV-1. We are currently testing the hypothesis that AC with measurable cognitive deficits has higher proviral loads than AC with normal neuropsychological tests. If this proves to be true then cognitive dysfunction could be included among the neurological manifestations of HTLV- 1 .

In summary, we found that, in this sample, HTLV-1 infection was associated with mild cognitive deficits as demonstrated by psychomotor slowing, decreased verbal fluency, deficits in verbal memory recover and recognition, visual memory deficit, selective and alternate attention deficits (flexibility), and impairment in visuoconstructive abilities. Also, we found that those deficits are independent of the presence of a myelopathy. Although this cognitive dysfunction is mild, it could be enough to impair the patient's quality of life.

\section{APPENDIX}

\section{Abbreviation list}

DSY, digit symbol test; GDOM, grooved pegboard test with dominant hand; GNDOM, grooved pegboard test with non-dominant hand; STRC, Stroop color test; STRCW, Stroop color-word test; F/A/S, fluency test (words begins with F, A, and S; animals/fruit, fluency test (name of animals and fruit); DSF, digit span forward; DSB, digit span backward; REYl/ REY2/ REY\%, Rey-Osterrieth complex figure; LM1/LM2/LM\%, logical memory test; RAl/RA5/RAF/RAF2/RAF 3/REV1/REV2/ REC, words list of Rey; TRAIL A, trail making test part A; TRAIL B, trail making test part B.

\section{Authors' affiliations}

M T T Silva, A Q-C Araújo, The Federal University of Rio de Janeiro and Evandro Chagas Clinical Research Institute/FIOCRUZ, Brazil P Mattos, A Alfano, The Institute of Psychiatry, The Federal University of Rio de Janeiro

Funding: this work was partially sponsored by a grant from the Brazilian Research Council (CNPq).

Competing interests: none declared.

\section{REFERENCES}

1 Osame M, Usuku K, Izumo S, et al. HTLV-I associated myelopathy, a new clinical entity. Lancet 1986;i:1031-2.
2 Poiesz BJ, Ruscetti FW, Gazdar AF, et al. Detection and isolation of type $C$ retrovirus particles from fresh and cultured lymphocytes of a patient with cutaneous T-cell lymphoma. Proc Natl Acad Sci USA 1980;77:7415-19

3 Vernant JC, Smadja D, Deforge-Lasseur C. Vasculitis ad neurologic manifestations related to HTLV-I. Presse Med 1994;23:1421-5.

4 Mora CA, Garruto RM, Brown P, et al. Seroprevalence of antibodies to HTLV-I in patients with chronic neurological disorders other than tropical spastic paraparesis. Ann Neurol 1988;23 (suppl):S192-5.

5 Bhigiee AI, Bill PL, Wiley CA, et al. Peripheral nerve lesions in HTLV-I associated myelopathy (HAM/TSP). Muscle Nerve 1993;16:21-6.

6 Nakao K, Isashiki Y, Uto M, et al. [Antibodies to human T-cell lymphotropic virus type 1 in the aqueous humor of HTLV-I associated uveitis]. Nippon Ganka Gakkai Zasshi 1994;98:866-71.

7 Cartier L GA, Araya F, Castillo JL. Cognitive function in progressive spastic paraparesis associated to HTLV-l: A preliminary study. Rev Chil Neuro-Psiquiat 1992;30:241-6.

8 Cartier L, Gormaz A. [Subcortical dementia in HTLV-I tropical spastic paraparesis. Study of 43 cases]. Rev Med Chil 1999;1 27:444-50.

9 Castillo JL, Camposano S, Cartier L, et al. Event related potentials in progressive spastic HTLV-I positive and negative paraparesis. Rev Chil Neuro-Psiquiat 1995;33:45-50.

10 Cartier L, Gormaz A, Kleinsteuber K, et al. ][New form of subcortical dementia: encephalopathy due to infection with human lymphotropic $T$ virus (HTLV-1). Clinical case]. Rev Med Chil 1997;125:209-13.

11 Cartier L MC, Araya F, Castillo JL, et al. Subacute encephalomyelopathy associatd with HTLV-I: pseudobulbar paralysis and mental deterioration. Neurology 1990:40 (suppl 1):238.

12 Lycke J, Svennerholm B, Svenningsson A, Horal P, et al. Possible association of HTLV-I infection and dementia. Acta Neurol Scand 1993;88: 199-203.

13 Fukushima $T$, Uyama $E$, Uchino $M$, et al. Cognitive event-related potentials and brain magnetic resonance imaging in HTLV-I associated myelopathy (HAM). J Neurol Sci 1994;126:30-9.

14 Kira J, Hamada T, Kawano Y, et al. An association oh HTLV-I infection with vascular dementia. Acta Neurol Scand 1997;96:305-9.

15 Sulkava R, Korpela J, Erkinjuntti T. No antibodies to HTLV-I and HIV in patients with dementia in Finland. Acta Neurol Scand 1987;76:155-6.

16 Osame M. Review of WHO Kagoshima meeting and diagnostic guidelines for HAM/TSP. In: Blattner W, ed. Human retrovirology: HTLV. New York: Raven Press, 1990:191-7.

17 Oliveira ALA, Bastos Fl, Afonso CR, et al. Measurement of neurological disbility in HTLV-I associated myelopathy: validation of a new clinical scale. AIDS Res Hum Retroviruses 2001; 17:S65.

18 Lesak MD. Batteries for assessment of brain damage - batteries for assessing specific conditions/HIV+. In: Lesak MD, ed Neuropsychological assessment. New York: Oxford Univesity Press, 1995:723.

19 Brandt J, Butters N. The neuropsychology of Huntington's disease. Trends Neurosci 1986;9:118-20.

20 Brandt J, Folstein S, Folstein M. Diferential cognitive impairment in Alzheimer's disease and Huntington's disease. Ann Neurol 1988;23:555-61.

21 Lesak MD. Neuropsychological Assessment. New York: Oxford University Press, 1995

22 Tournier-Lasserve E, Gout O, Gessain A, et al. HTLV-I, brain abnormalities on magnetic resonance imaging, and relation with multiple sclerosis. Lancet 1987;ii:49-50.

23 Hara Y, Takahashi M, Yoshikawa H, et al. [HTLV-I associated myelopathy with multiple spotty areas found in the cerebral white matter and brain stem by MRI]. Rinsho Shinkeigaku 1988;28:92-6.

24 Akizuki S, Setoguchi M, Nakazato O, et al. An autopsy case of human T-lymphotropic virus type l-associated myelopathy. Hum Pathol 1988; 19:988-90

25 Biddison WE, Kubota R, Kawanishi T, et al. Human T cell leukemia virus type I (HTLV-I)-specific CD8+ CTL clones from patients with HTLV-I-associated neurologic disease secrete proinflammatory cytokines, chemokines, and matrix metalloproteinase. J Immunol 1997; 159:201825.

26 Stoolman LM. Adhesion molecules controlling lymphocyte migration. Cell 1989;56:907-10.

27 Castro-Costa CM. Fisiopatologia de la paraparesia espástica tropical asociada con el retrovirus HTLV-I. In: Zaninovic V, Castro-Costa CM, eds. La paraparesia espástica tropical o mielopatia asociada con el HTLV-I. Bogotá: Colciencias, 1998:91-115.

28 Yu F, Itoyama Y, Kira J, et al. TNF-beta produced by HTLV-I-infected cells influences the proliferation of human endothelial cells and fibroblasts. $J$ Immunol 1994;152:5930-8

29 Yoshida S, Minakawa T, Takai N, et al. Effects of cytokines on cultured microvascular endothelial cells derived from gerbil brain. Neurosurgery 1989;25:373-7.

30 Filley CM. The behavioral neurology of cerebral white matter. Neurology 1998;50:1535-40

31 Mesulan M-M. Prefrontal heteromodal cortex and frontal lobe syndromes: attention, executive functions and comportment. In: Mesulan $M-M$, ed. Principles of behavioral and cognitive neurology. 2 nd edn. New York: Oxford University Press, 2000:41-9.

32 de Groot JC, de Leeuw FE, Oudkerk M, et al. Cerebral white matter lesions and cognitive function: the Rotterdam Scan Study. Ann Neurol 2000;47: 145-51

33 Manns A, Miley WJ, Wilks R, et al. Quantitative proviral DNA and antibody levels in the natural history of HTLV-I infection. J Infect Dis 1999; 180: 1487-93. 
34 Taylor GP, Tosswill JH, Matutes E, et al. Prospective study of HTLV-I infection in an initially asymptomatic cohort. J Acquir Immune Defic Syndr 1999;22:92-100.

35 Kramer A, Maloney EM, Morgan OS, et al. Risk factors and cofactors for human T-cell lymphotropic virus type I (HTLV-I)-associated myelopathy/tropical spastic paraparesis (HAM/TSP) in Jamaica. Am J Epidemiol 1995;142:1212-20.

36 Leite AC. Prevalence study of neurologic manifestations in HTLV-I positive blood donors. Arq Neuropsiquiatr 2000;58:195.
37 Kira J, Fujihara K, Itoyama $Y$, et al. Leukoencephalopathy in HTLV-I-associated myelopathy/tropical spastic paraparesis: MRI analysis and a two year follow-up study after corticosteroid therapy. J Neurol Sci $1991 ; 106: 41-9$

38 Janssen RS, Saykin AJ, Kaplan JE, et al. Neurological symptoms and neuropsychological abnormalities in lymphadenopathy syndrome. Ann Neurol 1988;23 (suppl):S17-8.

39 Janssen RS, Saykin Al Kaplan JE, et al. Neurological complications of human immunodeficiency virus infection in patients with lymphadenopathy syndrome. Ann Neurol 1988;23:49-55.

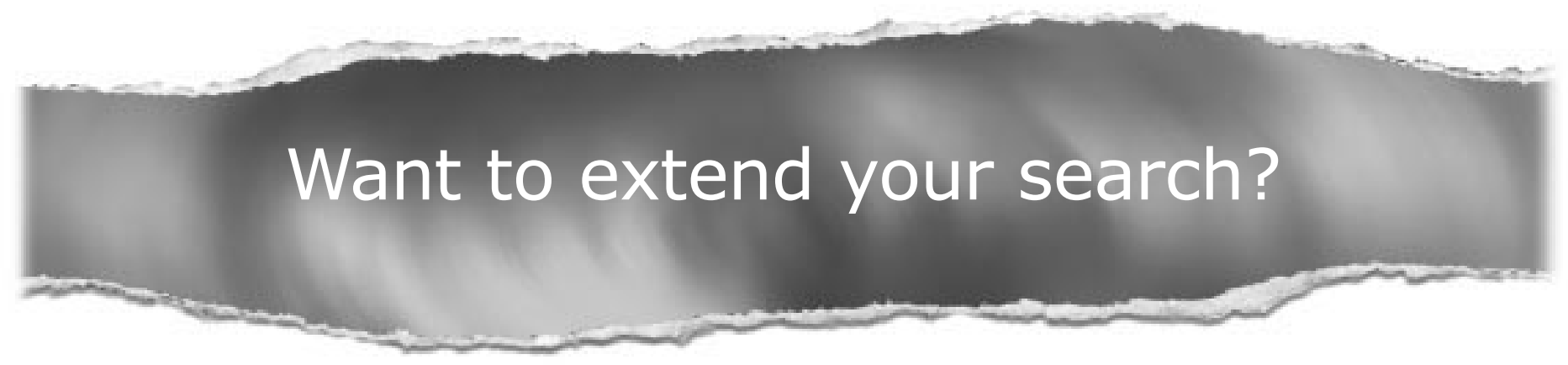

Cross journal searching

Can't find what you're looking for in Journal of Neurology, Neurosurgery, and Psychiatry? Extend your search across $340+$ journals. Search restriction options include specific subject areas (eg. clinical medicine, basic research), select specific journals or search all available titles.

www.jnnp.com 